The INL is a

U.S. Department of Energy

National Laboratory

operated by

Battelle Energy Alliance

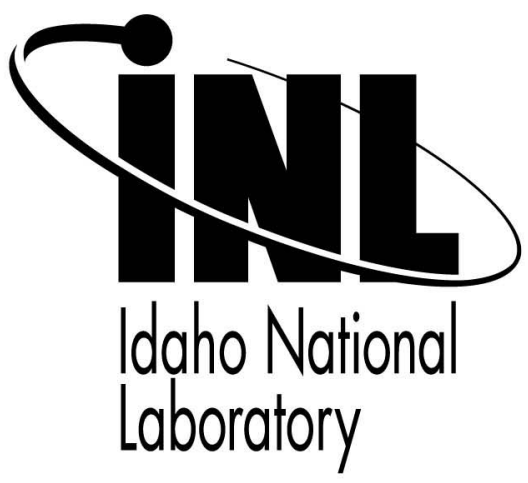

\title{
Applying SE Methods
} Achieves Project Success to Evaluate Hammer and Fixed Cutter Grinders Using Multiple Varieties and Moistures of Biomass Feedstock for Ethanol Production

\section{$18^{\text {th }}$ Annual Symposium of the International Council on Systems Engineering}

\author{
Larry R. Zirker \\ Christopher T. Wright \\ R. Douglas Hamelin
}

June 2008

This is a preprint of a paper intended for publication in a journal or proceedings. Since changes may be made before publication, this preprint should not be cited or reproduced without permission of the author. This document was prepared as an account of work sponsored by an agency of the United States Government. Neither the United States Government nor any agency thereof, or any of their employees, makes any warranty, expressed or implied, or assumes any legal liability or responsibility for any third party's use, or the results of such use, of any information, apparatus, product or process disclosed in this report, or represents that its use by such third party would not infringe privately owned rights. The views expressed in this paper are not necessarily those of the United States Government or the sponsoring agency. 


\title{
Applying SE Methods Achieves Project Success to Evaluate Hammer and Fixed Cutter Grinders Using Multiple Varieties and Moistures of Biomass Feedstock for Ethanol Production
}

\author{
Larry R. Zirker, MS \\ Idaho National Laboratory \\ Battelle Energy Alliance \\ 2525 N. Fremont Ave \\ Idaho Falls, ID, 83415-3830 \\ 1-208-526-0152 \\ larry.zirker@inl.gov
}

\author{
Christopher T. Wright, $\mathrm{PhD}$ \\ Idaho National Laboratory \\ Battelle Energy Alliance \\ 2525 N. Fremont Ave \\ Idaho Falls, ID, 83415-2210 \\ 1-208-526-3075 \\ christopher.wright@inl.gov
}

\author{
R. Douglas Hamelin, MA \\ Idaho National Laboratory \\ Battelle Energy Alliance \\ 2525 N. Fremont Ave \\ Idaho Falls, ID, 83415-3780 \\ 1-208-526-2337 \\ douglas.hamelin@inl.gov
}

\begin{abstract}
Applying basic systems engineering (SE) tools to the mission analysis phases of a 2.5million dollar biomass pre-processing project for the U.S. Department of Energy directly assisted the project principal investigator understand the complexity and identify the gaps of a movingtarget project and capture the undefined technical/functional requirements and deliverables from the project team and industrial partners. A creative application of various SE tools by nonaerospace systems engineers developed an innovative "big picture" product that combined aspects of mission analysis with a project functional flow block diagram, providing immediate understanding of the depth and breath of the biomass preprocessing effort for all team members, customers, and industrial partners. The "big picture" diagram became the blue print to write the project test plan, and provided direction to bring the project back on track and achieve project success.
\end{abstract}

\section{Introduction: The Problem with Applying Systems Engineering in the Non-Defense/Non-Aerospace Environment}

It is readily known that systems engineering (SE) has its roots in the aerospace and defense industries, and most text books germane to SE are based on electronic, aeronautical, and defense project test cases. But as an engineering discipline, SE is largely unknown and misunderstood in other areas or fields of study. As such, countless opportunities exist for SE application in agriculture, environmental, nuclear, and other non-defense, non-aerospace programs and projects.

A dilemma exists with non-traditional applications of SE in that systems engineers often "preach" the merits of SE or try to "force" SE methods on the non-traditional customer. These approaches tend to be overbearing and most often result in information overload and a resistance to those very principles that will help ensure project success. Further, systems engineers often promote state-of-the-art tools and techniques that over-extend budgets and schedules, or they get wrapped around the complexities of the problem and fail to apply the simple approaches that add real value to the program or project. An illustration of this is the well-intentioned systems engineer who is brought on midway through a project and attempts to "start over" with a 
rigorous SE approach that both frustrates project management and imposes further delays on project deliverables.

As systems engineers who regularly provide non-traditional SE support on both small and large projects, the authors are often recruited in later life-cycle phases to assess struggling projects and help them meet pending milestones. These situations have proven time and again the over-riding value of simple, fundamental SE tools and techniques, but often require a more creative and adaptive application of those tools and techniques that gives project managers what they immediately want and need. A secondary outgrowth of this type of tailored application of SE with a non-aerospace project manager is the all important follow-on work for the systems engineer. Most often, the follow-on work occurs at the beginning of the subsequent phases of the project because the managers have seen the value of applying basic SE tools and techniques.

Systems engineers at the Idaho National Laboratory (INL) recently applied simple, fundamental SE techniques in the late stages of an on-going agricultural/energy project, resulting in the project meeting several critical milestones that would otherwise have been missed. The approach, which is describe in detail below, allowed the project manager and principle investigator to quickly focus on immediate needs while validating overall project direction and establishing a basis for future, system-based project management opportunities via a more rigorous SE application.

The goal of this paper is to explain how this agricultural/energy-related project borrowed, applied, and adapted fundamental SE tools and techniques to achieve project success.

\section{Project Background}

Biomass pre-processing is a critical operation in the preparation of feedstock for the frontend of a cellulosic ethanol biorefinery. Its purpose is to chop, grind, or otherwise format the biomass material (wheat straw, corn stover, etc.) into a suitable feedstock particle size for conversion to ethanol and other bio products (see Figure 1).

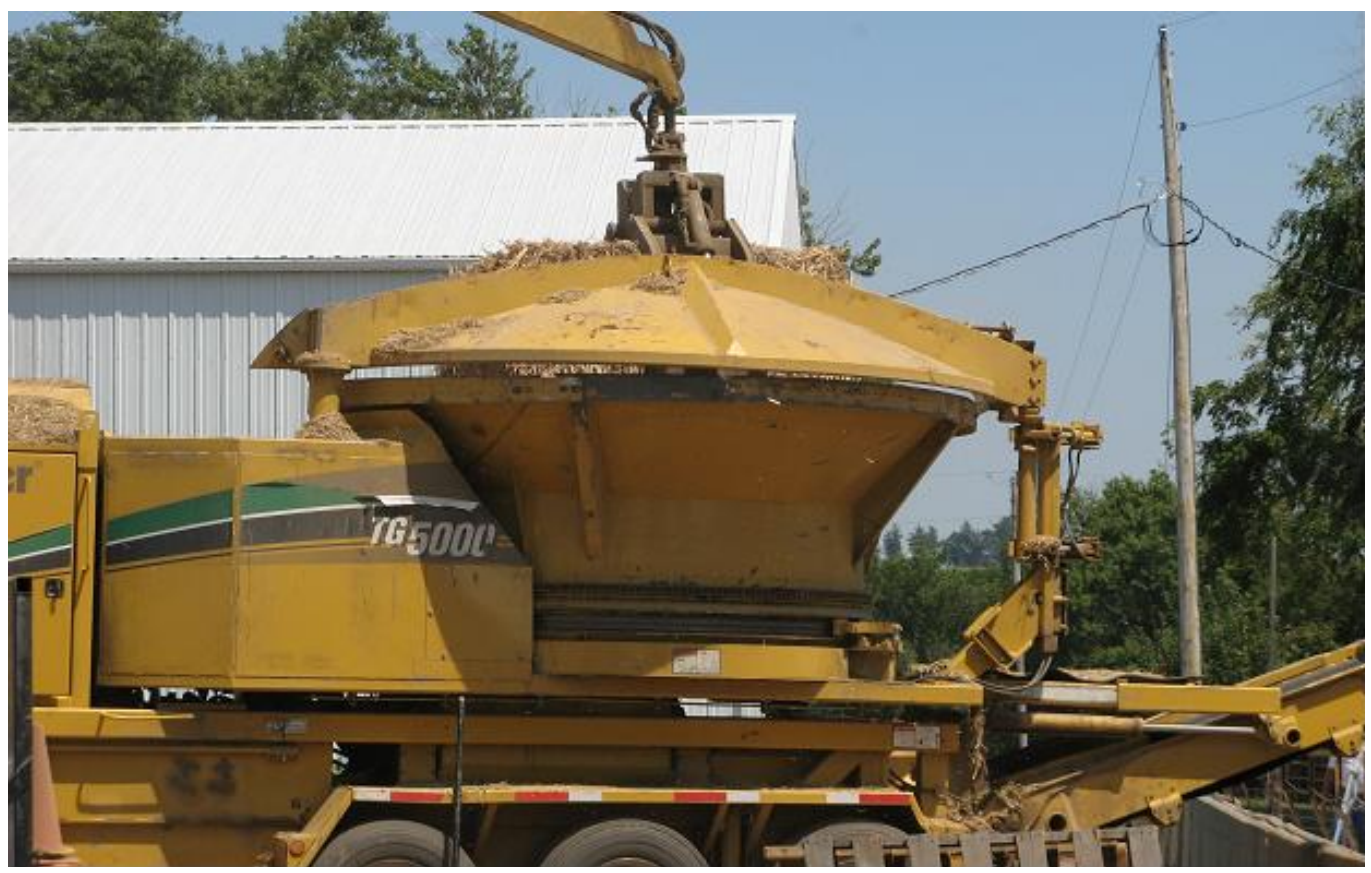

Figure 1. Grinding of corn stover 
Without this operation, the natural size, bulk density, and flowability characteristics of harvested biomass would decrease the capacities and efficiencies of feedstock assembly unit operations and biorefinery conversion processes to the degree that programmatic cost targets could not be met. Thus, the pre-processing unit operation produces a bulk flowable material that:

1. Improves handling and conveying efficiencies throughout the feedstock assembly system and biorefinery

2. Increases biomass surface areas for improved pretreatment efficiencies

3. Reduces particle sizes for improved feedstock uniformity and density.

In addition, biomass pre-processing has the potential to change traditional methodologies for collecting, handling, and transporting biomass that could lead to revolutionary improvements in the feedstock assembly system.

The U.S. Department of Energy (DOE) and the U.S. Department of Agriculture (USDA) are both strongly committed to expanding the role of biomass as an energy source (Biomass 2006; Biomass 2007; Riley 2007). This project directly supports developing biomass fuels and products to reduce the need for oil and gas imports; reduce global warming; support the growth of agriculture, forestry, and rural economies; and foster major new domestic industries biorefineries - making a variety of fuels, chemicals, and other products.

The INL is directly tasked with determining the overall efficiency of the feedstock supply systems, including the harvest and collection, storage, pre-processing (grinding), transportation, and handling unit operations for all feedstock types used in bioethanol or syngas production.

Field grinding tests consisted of running $1000 \mathrm{lbs}\left(4^{\prime} \times 4^{\prime} \times 8^{\prime}\right.$ square) bales of barley straw through six different grinder screen size configurations. The test configurations were designed to demonstrate hammer and fixed cutter grinder performance targets for a capacity of 30 tons/hour, a particle size of $1 / 4$-inch minus, and a bulk density of $8 \mathrm{lbs} / \mathrm{ft}^{3}$ or greater.

For the 2007 phase of the project, a full-scale grinding research demonstration collected hammer and fixed cutter grinder performance data for different commercial grinder technologies on multiple feedstock varieties and moisture levels. This work focuses on identifying the performance parameters of three aspects of a grinding system, specifically the loading or feeding of biomass materials into the grinders, fractionation of the feed stock, and screen separation systems. In addition, this work used fundamental bulk biomass characterization methods to help improve and eventually optimize the performance parameters of each aspect of a grinding machine. The final feedstock preprocessing system design will identify a clear path to further demonstrate and validate the preprocessing unit operation by FY-09.

\section{Project Dilemma}

In the spring of 2007, the author found the feedstock pre-processing project engineer sitting at his desk surrounded by a dozen SE text books trying to determine a starting point for writing a test plan for the 2007 full-scale feedstock grinding demonstration project. The project engineer explained that the project start date was at risk of slipping, the project requirements were a moving target, the tasks were not defined, and several project deliverables were required by year end. Further, the project needed to collect hammer and fixed cutter grinder performance data on 
multiple feedstock varieties and moisture levels by purchasing, staging, and ultimately grinding 800,000 pounds of media by the end of the year by three undefined commercial grinder vendors. The author offered to serve as the project systems engineer and to apply a few simple SE techniques that would greatly help the project meet its deliverables. The project engineer accepted the offer.

\section{Systems Approach}

The primary task given to the project systems engineer was to produce a project test plan to grind 800,000 pounds of feedstock media in 2007 . While the primary goal was to write a test plan, a multitude of unidentified project tasks, requirements, deliverables, and objectives needed to be defined before the test plan could be written. In essence, the project had to understand the question before it could start designing the answer (Martin 1997). Furthermore, collaborations with industrial partners had to be arranged, contracts written to purchase feedstock, staging areas located for the grinding tests, and research personnel/laboratories secured before the end of the year.

As is often the case, there was not sufficient time or resources to "start over" and gather all of the information typically gleaned through an end-to-end SE approach. Rather, the systems engineer had to devise a simplified way to achieve typical SE outcomes without compromising project budgets or schedules. A chronology of the resulting SE approach, showing the application of fundamental SE tools and techniques to meet the needs of the project, is as follows:

- Parse already documented requirements and populate a requirements matrix as a basis for validating existing tasks and deliverables

- Develop a project functional flow block diagram to show the interrelationship of project tasks

- Conduct a mission analysis

- Clarify the problem statement

- Articulate project objectives

- Define required hardware and personnel needs

- Generate a system-of-systems or "big picture" diagram that integrates aspects of the mission analysis and functional analysis into a single product

- Write the project test plan.

\subsection{Initial SE Work}

The initial SE effort focused on defining the project requirements by parsing the requirements from the project proposal documents. In this case, parsing means to break into component parts by reading the text of documents to sort the requirements statements from the non-requirements of the text (Zirker 2005). Concurrent with the parsing effort, a simple 
requirements matrix was initiated, but it was quickly discovered that the project documents lacked configuration control and that many of the current customer and industrial partner requirements were undocumented.

A quick assessment of the effort required to correct this deficiency concluded that it was too late in the life of the project to do a complete requirements analysis. By the time all of the undocumented requirements could be defined and articulated, it would neither help nor add value to the project. A decision was made not to expend the effort on capturing the undocumented requirements at this time, but rather to focus on capturing/validating the project tasks or functions upon which the test plan would be based. Although, it hedges on SE heresy, the assumption was that the team of engineers and scientists "knew" the requirements, and that they were valid. It was agreed that defining the project functions and tasks would optimize or advance the work in three ways:

- Capture all of the project functions and tasks necessary to move forward with the 2007 work scope

- Force project team members to articulate and document their individual functions/tasks

- Provide a basis from which to write the project or test plan.

\subsection{Functions, Tasks, and Deliverables}

Since the project was at risk of falling behind schedule and given the many engineers and scientists involved, it was further decided that a project functional flow block diagram (FFBD) would be the ideal tool to both assess the project stage and to identify project gaps. Over the next few weeks, the FFBD proved to be an ideal tool for extracting from the minds of the project staff (1) what had to be done to achieve project milestones and (2) what gaps existed in the flow of necessary project tasks/functions. The four major sections or aspects of the FFBD were divided into following swim lanes:

- Conduct machine and ground material characterization tests (preliminary testing to define the optimum grinding profile of hammer milling equipment on the specific feedstock media)

- Mobilize for full-scale testing at the test site (the steps for staging 800,000 pounds of feedstock at the test site)

- Conduct machine capacity and bulk density characterization tests (expanded grinding [30-ton batches] to define machine capacity and media density)

- Analyze samples (what was to be done with the grinding data and ground media samples).

It should be noted that the FFBD used for this effort was a simple adaptation of a traditional FFBD, not showing a decomposition hierarchy of numbers or links to a paragraph number from the requirements document. Rather, it delineated the order in which tasks had to be performed 
and included ancillary notes and explanations, as needed. A section of the FFBD is shown in Figure 2.

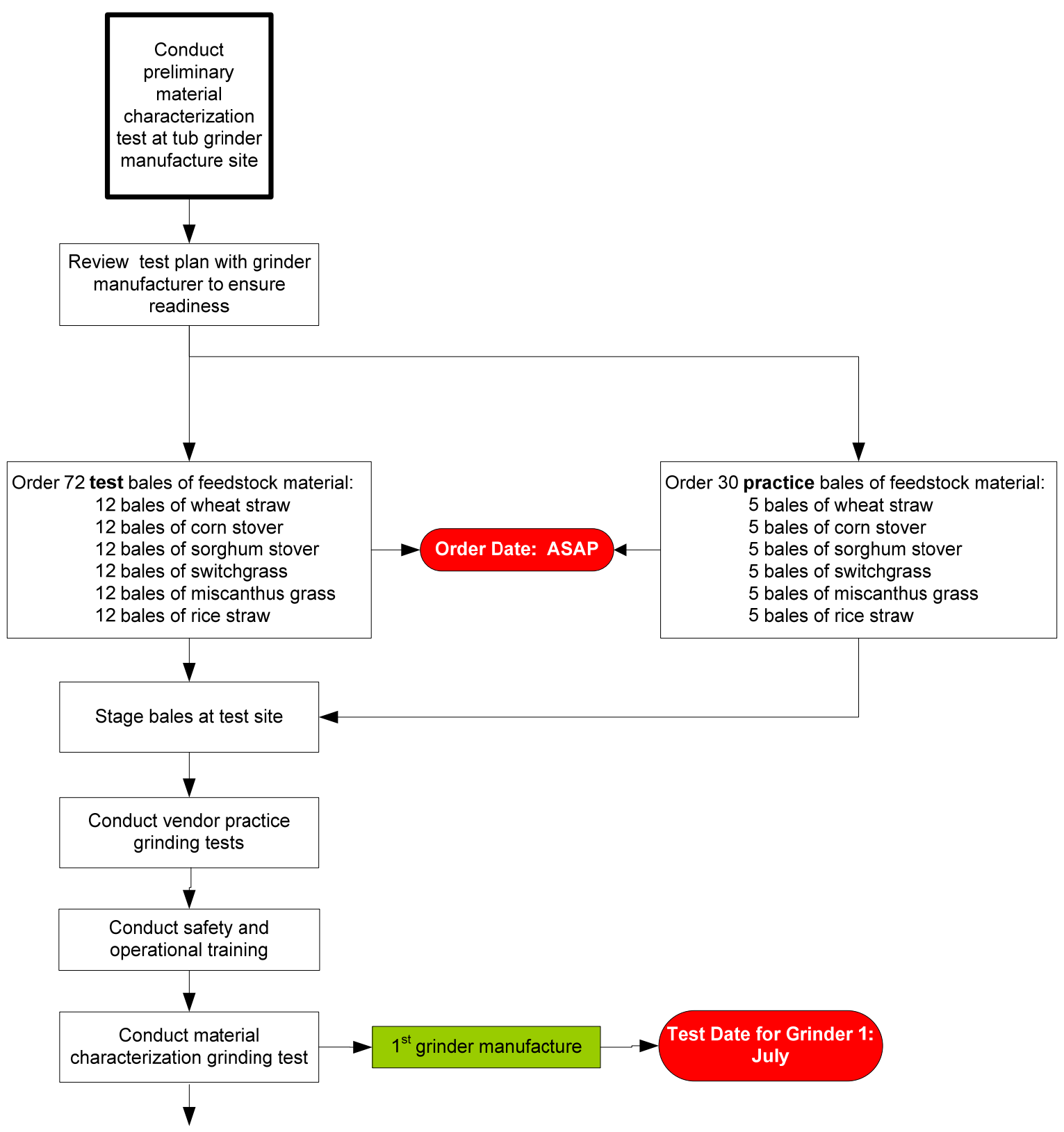

Figure 2. Excerpt from simplified biomass feedstock FFBD

After a few iterations, it was observed that the FFBD was providing interesting artifacts:

- By illustrating the depth and breadth of a heretofore undefined project, the diagram greatly improved understanding between the team members of what others were doing and what tasks had yet to be done.

- Team member began to see their individual place within the whole system. 


\subsection{Mission Analysis}

Since the "big picture" had never before been articulated to project personnel, it was decided to expand beyond the functional analysis described above and conduct a mission analysis to define the "big picture" for the scientists and engineers who often can't (or don't) comprehend the whole of the project from the $100+$ pages of text and tables that typically comprise the governing project documentation. Non-engineering/non-scientific industrial partners also needed to be able to see the big picture, so it was decided that value would be added to the project if the project mission analysis could be graphically presented.

Several traditional elements of mission analysis were performed to compile the big picture view. A large list of general project objectives was also developed, but since the project had already been divided into four separate aspects, shown in the swim lanes of the FFBD (see Section 4.2), it was decided to bin the objectives into each of the four project aspects. Figure 3 shows the objectives identified for one of the four project aspects.

Conduct Machine and Ground Material Characterization Test

- To characterize grinder technologies

- To characterize deconstruction profile of ground feedstock per screen sizes

- To characterize bulk density of ground feedstock per screen sizes

- To define the optimum target particle size for full scale efficiency test

Figure 3. One project aspect with associated objectives

The four project aspects also provided an excellent decomposition for defining the hardware and personnel needs since they are unique to each aspect (see Figure 4).

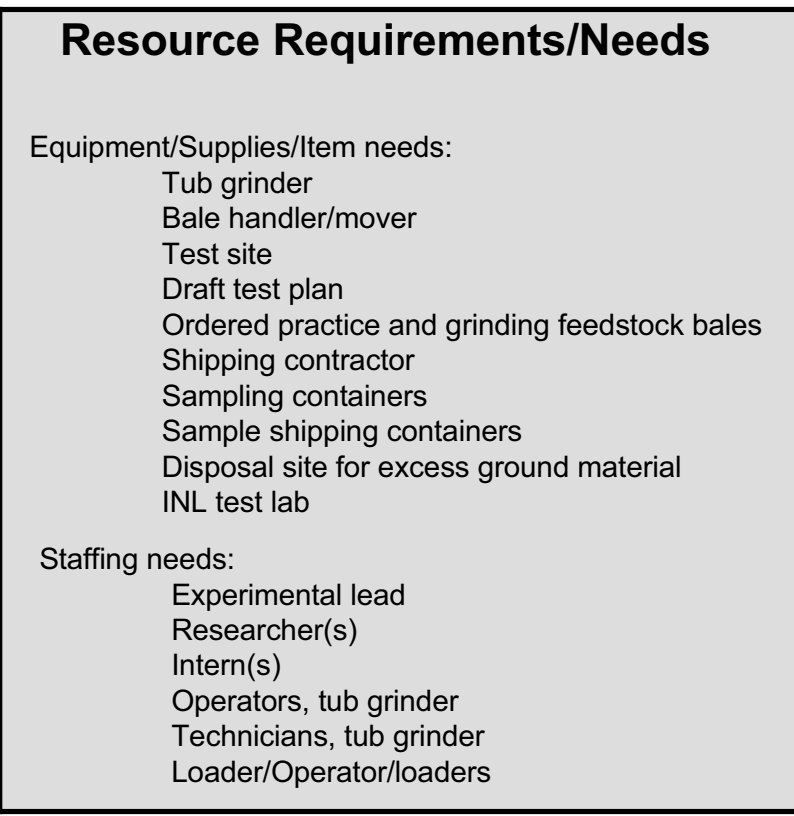

Figure 4. resource requirements and needs 


\subsection{Big Picture Diagram (Mission Analysis meets FFBD)}

The twist of the mission analysis effort was to superimpose the mission analysis elements directly onto the FFBD diagram to graphically show the big picture of the project. This was accomplished by reformatting the FFBD as a project flow diagram with associated mission elements, as follows:

- The problem statement became the new title of the FFBD.

- The functions were organized into swim lanes corresponding to the four project aspects, and the objectives of the four aspects were listed underneath the associated FFBD swim lanes.

- The detailed list of resource requirements and needs was placed within each of the swim lanes to show the different requirements for each of the project aspects.

- The paper size for the FFBD was expanded to the maximum the plotter would support $-34 " \times 44 "$ (E-size) to hold all of the additions.

When the customers, industrial partners, and other team members were shown the new diagram and talked through the project, they had both immediate and complete understanding of the project big picture for the first time. The graphic was printed dozens of times because the team and industrial partners each wanted a copy. The real benefit of the big picture graphic, however, was that it provided a baseline from which to build the Project Test Plan.

\subsection{Test Plan}

Writing the project test plan was the initial and primary goal of the authors. That task could now begin since nuances of the previously undefined project were now captured and documented. The two major aspects of the test plan were:

- Conduct Machine and Ground Material Characterization Test

- Conduct Machine Capacity and Bulk Density Characterization Test.

The Machine and Ground Material Characterization Test had to be conducted first to generate or characterize the grinding machines and ground material enough to select optimized conditions for the larger Machine Capacity and Bulk Density Characterization Test.

A graphic showing the functional decomposition of the tests was patterned after the FFBD graphic and is shown in Figure 5. This figure became the outline for both of the experimental tests in the test plan. 

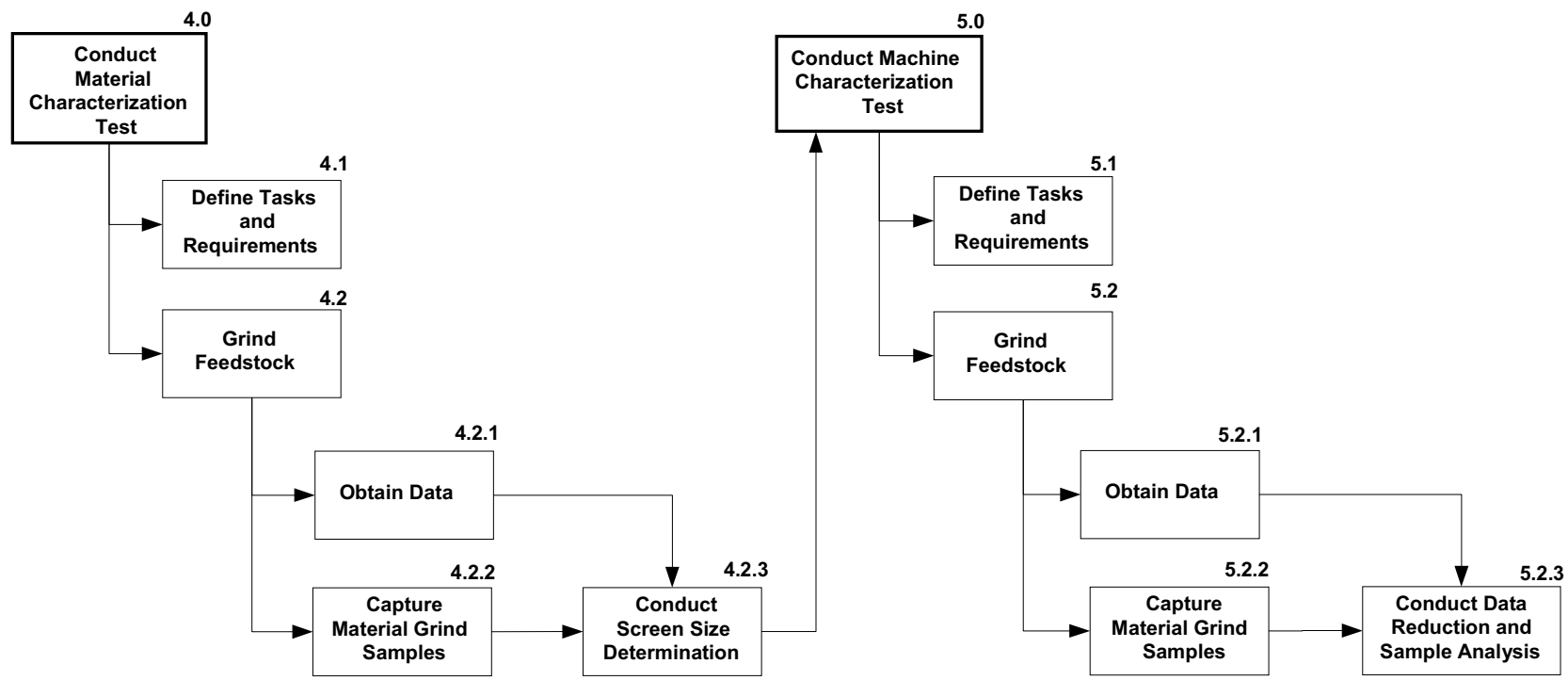

Figure 5. General experimental tasks and activities of the draft test plan

The big picture diagram provides much of the data needed to write the test plan. One additional SE tool was deployed within the test plan with great success, a modified requirement matrix. This matrix was used in each section to document what was to be done, who was to do it, the resulting deliverable, and any notes germane to the task. These matrices provided the tool for the authors to extract derived tasks from the performers and articulate the deliverables. Two rows of the Section 5.1.1 General Tasks, Performers, and Deliverables matrix are shown in Table 1.

Table 1. Section 5.1.1 general tasks, performers and deliverables

\begin{tabular}{|l|l|l|l|}
\hline \multicolumn{1}{|c|}{ Tasks } & \multicolumn{1}{|c|}{ Performer } & \multicolumn{1}{c|}{ Deliverable } & \multicolumn{1}{c|}{ Notes } \\
\hline $\begin{array}{l}\text { Conduct Operational } \\
\text { safety meeting }\end{array}$ & $\begin{array}{l}\text { Entire Field } \\
\text { Team }\end{array}$ & Operational training & $\begin{array}{l}\text { This training, conducted by the grinder } \\
\text { manufacture, will be relevant to the operation of } \\
\text { the grinder and loading equipment. Other } \\
\text { hazards such as fire, noise, and dust will also be } \\
\text { addressed. Personal Protection Equipment } \\
\text { (PPE) will be provided as needed. }\end{array}$ \\
\hline $\begin{array}{l}\text { Grind } 30 \text { tons }(\sim 60 \\
\text { bales) of corn stover } \\
\text { at moisture 1 }\end{array}$ & $\begin{array}{l}\text { Loader } \\
\text { operator and } \\
\text { grinder team }\end{array}$ & $\begin{array}{l}30 \text { tons of corn } \\
\text { stover ground } \\
\text { material }\end{array}$ & $\begin{array}{l}\text { Loader operator will keep a continuous supply of } \\
\text { feedstock in the grinder to ensure the grinder is } \\
\text { working at maximum capacity }\end{array}$ \\
\hline
\end{tabular}

\section{Project Success}

This simplified introduction to SE for the biomass project resulted in the project successfully meeting all 2007 milestones. Project success can be attributed to the following:

- The project was brought back on track through the use of simple SE tools and techniques that gave the customer what they wanted in a cost-effective, timely, and unobtrusive manner. 
- The project systems engineers provided flexible and creative deployment of SE tools and techniques that gave the customer what they needed without promoting more complex, state-of-the-art tools and techniques that would have over-extended already tight budgets and schedules.

- The project met all of its 2007 goals largely due to the two documents resulting from the tailored SE approach - the modified, "big picture" FFBD diagram and the Project Test Plan. These two documents:

- Captured all of the project tasks that were required to be performed in 2007.

- Provided clarity and understanding to customers, team members, and industrial partners regarding the complexity of the project to find, purchase, and grind 800,000 pounds of feedstock media with three commercial hammer and fixed cutter grinders.

- Detailed when and how to capture the hundreds of ground media and machine data points needed for the subsequent analysis by the project scientists.

- Provided a systems approach, ensuring all project functions and tasks were both identified and accomplished.

- The modified, "big picture" FFBD diagram and the Project Test Plan were also largely successful because the project leadership committed to the system engineers to provided daily support, if needed, to ensure they were complete and published on time.

\section{Conclusion}

Based on this and similar experiences, the authors conclude that the successful introduction of SE principles to non-defense/non-aerospace professionals can be readily accomplished through the simplified, tailored application of fundamental SE tools, techniques, and methods that quickly and efficiently demonstrate the value of SE principles. The biomass feedstock project shows that a systems engineer needs to be flexible enough to give the customer what they want, but creative enough to adapt SE techniques to give them what they need. Although SE was applied during the project to achieve the desired results, it was mainly successful because it was an application of good engineering practices in a quantity and level of rigor palatable to those otherwise unfamiliar with the SE discipline.

\section{Epilogue}

Due to successes achieved by the project systems engineers, they were given the opportunity to conduct similar analyses for the overall program, of which the biomass pre-processing project is only a part. This broader effort employed more revolutionary visualization tools to allow program participants to capture the elements and interfaces of the entire project in a single graphic, known as a Zoned Analysis (Zirker 2005). Additionally, the project systems engineers have been asked to join the project team for subsequent phases of the project to (1) conduct a 
detailed requirements analysis and ensure project tasks are linked to requirements, and (2) to perform a gap analysis between products, personnel, and system designs.

\section{References}

Biomass Research and Development Initiative. 2006. Vision for bioenergy and biobased products in the United States: Bioeconomy for a sustainable future. Washington, D.C: U.S. Department of Energy Office of Energy Efficiency and Renewable Energy, Office of the Biomass Program. http://www1.eere.energy.gov/biomass/pdfs/final_2006_vision.pdf.

. 2007. Roadmap for bioenergy and biomass products in the United States. Washington, D.C: U.S. Department of Energy Office of Energy Efficiency and Renewable Energy, Office of the Biomass Program.

http://www1.eere.energy.gov/biomass/pdfs/obp_roadmapv2_web.pdf.

Martin, J. N. 1996. Systems engineering guidebook: A process for developing systems and products. Boca Raton, FL: CRC Press.

Riley, C., D. Sandor, and P. Simpkins. 2007. Using CORE model-based systems engineering software to support program management in the U.S. Department of Energy Office of the Biomass Program. In Proceedings of the Seventeenth Annual International Symposium of the International Council on Systems Engineering (San Diego, CA). Seattle: INCOSE.

Zirker, L., and R. D. Hamelin. (2005). "Works for me!!" Three fundamental SE techniques for beginners to apply the systems approach. In Proceedings of the Fifteenth Annual International Symposium of the International Council on Systems Engineering (Rochester, NY). Seattle: INCOSE.

\section{Biography}

Larry Zirker (MS, Welding Engineering, The Ohio State University) worked for 25 years in the energy field and is a senior scientist/engineer for Battelle Energy Alliance at the Idaho National Laboratory working both large and small projects and worked nine years in the System Engineering Department. Mr. Zirker works primarily on the front end of projects defining project requirements, tasks, special needs, deliverables and interfaces with customers and task performers. He developed a unique circular work breakdown structure technique, Zoned Analysis, that regularly helps customers and team members see the big picture. Mr. Zirker published two previous times at INCOSE conferences.

Dr. Christopher T. Wright ( $\mathrm{PhD}$, Mechanical Engineering, Utah State University), research engineer for the Idaho National Laboratory in the Bioenergy Program, has over nine years of experience in applied solid mechanics, fluid dynamics, thermal hydraulics, and two-phase flow. Dr. Wright's work includes investigating the flow separation process of agricultural residues in agricultural machinery. His work has been applied to formatting characteristics of biomass feedstocks for use in a cellulosic biorefinery. Dr. Wright's work supports the bioenergy effort to demonstrate a cost and quality effective feedstock assembly system for the emerging cellulosic ethanol industry. His research is demonstrated through integrated feedstock supply chain analysis and demonstration.

R. Douglas Hamelin (MA, English, Idaho State University) has worked for the Idaho National Laboratory Systems Engineering organization for nearly 15 years, specializing in 
systems engineering documentation. Mr. Hamelin is also trained in requirements management using DOORS and CORE, and contributes to a wide range of systems engineering applications as a functional analyst. Additional contributions to systems engineering include facilitation and computer-aided decision support using a variety of software and internet applications. Mr. Hamelin is a co-author on numerous Department of Energy publications 